\section{Response to: 'Lack of standardization of ANA and implications for drug development and precision medicine' by Mahler}

We appreciate Dr Mahler's ${ }^{1}$ comments on our paper, 'Assay variation in the detection of antinuclear antibodies in the sera of patients with established SLE', ${ }^{2}$ by Pisetsky and colleagues, and the thoughtful discussion on the technical issues that affect the testing for antinuclear antibodies (ANA) by immunofluorescence assays with HEp-2 cells (IFA). We agree that our sample size was relatively small and that we did not present confidence limits on the frequency of positive responses. Rather than attempting to revalidate the assays, we designed our study to correspond to the 'real world' situation that might occur in a clinical trial or clinical practice. In the real world, whatever the purpose of ANA testing, it is likely that an IFA will be performed by a single reader on a single occasion using only one kit; our study highlights the kit issue and the variable results obtained when the same sample is assayed with multiple kits. While our study involved only one reader, reader variability is well recognised and has provided the impetus to develop less operator-dependent tests including ELISAs, multiplex bead-based assays and computer-based imaging.

As our paper and Dr Mahler's discussion indicate, testing depends on context. Indeed, there are important differences in the use of the IFA to screen for an ANA-associated rheumatic disease in the clinic, on one hand, or to subset patients with systemic lupus erythematosus (SLE) in a clinical trial, on the other. Assay variability can be problematic in both settings; we believe that assay reliability is especially relevant in the treatment setting for SLE, whether to determine trial eligibility or prescription of a medication approved for 'active autoantibody positive' disease. Dr Mahler is right to point out the differences between a companion diagnostic and complementary diagnostic. As more clinical trials for new agents for SLE incorporate the testing for ANA (and anti-DNA) to assess eligibility and to inform labelling, this difference is critical.

In view of the importance of serology in establishing eligibility of patients for clinical trials as well as product labelling, we believe that regulatory agencies need to recognise the important issues with assay variability with current ANA tests and to develop guidance on the best approach to use serology in the development of new therapies for SLE.

\section{David S Pisetsky, ${ }^{1}$ Diane M Spencer, ${ }^{1}$ Peter E Lipsky, ${ }^{2}$ Brad H Rovin ${ }^{3}$}

${ }^{1}$ Department of Medicine and Immunology, Duke University Medical Center and Medical Research Service, VA Medical Center, Durham, North Carolina, USA

${ }^{2}$ RILITE Research Institute, Charlottesville, Virginia, USA

${ }^{3}$ Division of Nephrology, Wexner Medical Center, The Ohio State University, Columbus, Ohio, USA

Correspondence to Dr David S Pisetsky, Department of Medicine and Immunology, Duke University Medical Center and Medical Research Service, VA Medical Center, Durham, NC 27705, USA; david.pisetsky@duke.edu

Handling editor Josef S Smolen

Funding The authors have not declared a specific grant for this research from any funding agency in the public, commercial or not-for-profit sectors.

Competing interests None declared.

Patient consent Not required.

Provenance and peer review Commissioned; internally peer reviewed.

(c) Article author(s) (or their employer(s) unless otherwise stated in the text of the article) 2019. All rights reserved. No commercial use is permitted unless otherwise expressly granted.

\section{Check for updates}

To cite Pisetsky DS, Spencer DM, Lipsky PE, et al. Ann Rheum Dis 2019;78:e34.

Received 20 March 2018

Accepted 22 March 2018

Published Online First 28 March 2018

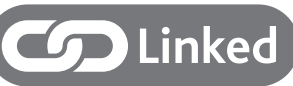

- http://dx.doi.org/10.1136/annrheumdis-2018-213374

Ann Rheum Dis 2019;78:e34. doi:10.1136/annrheumdis-2018-213399

\section{REFERENCES}

1 Mahler M. Lack of standardization of ANA and implications for drug development and precision medicine. Ann Rheum Dis 2019;78:e33.

2 Pisetsky DS, Spencer DM, Lipsky PE, et al. Assay variation in the detection of antinuclear antibodies in the sera of patients with established SLE. Ann Rheum Dis 2018;77:911-3. 